\title{
Green business models in the construction sector: An analysis of outcomes and benefits
}

\begin{tabular}{|r|l|}
\hline Journal: & Construction Innovation: Information, Process, Management \\
\hline Manuscript ID & CI-07-2016-0041.R2 \\
\hline Manuscript Type: & Research Article \\
\hline Keywords: & $\begin{array}{l}\text { Benefits, Construction, Green business models, Interpretive ranking } \\
\text { process, UK, Elements }\end{array}$ \\
\hline \multicolumn{2}{|l}{} \\
\hline
\end{tabular}

\section{SCHOLARONE ${ }^{\text {m }}$ \\ Manuscripts}




\title{
Green business models in the construction sector: An analysis of outcomes and benefits
}

\begin{abstract}
Purpose - The call to examine-Ggreen business models (GBMs) in the construction sector represent the logic of green value creation and capture. Hence, the call to examine GBMs is has been growing ever louder because they represent the logic of green value creation and eapture. The aim is to identify benefits of GBMs by adopting- five essential elements of the GBM from the literature: green value proposition (GVP); target group (TG); key activities (KA); key resources (KR); and financial logic (FL).

Design/methodology/approach -19 Nineteen semi-structured interviews are conducted with construction sector practitioners and academics in the UK. Thematic analysis is used to obtain benefits of GBMs. Further, the Interpretive Ranking Process (IRP) is used to examine which elements of the GBM have a dominant role in providing benefits to the-construction businesses.
\end{abstract}

Findings - The benefits are grouped into three themes: credibility/reputation benefits; financial benefits; and long-term viability benefits. The IRP model shows that the element of $\mathrm{KR}$ is the most important element-when evaluated against these three benefit themes.

Implications - Linking GBM elements and benefits will help companies in the construction sector to analyse the business case of embracing environmental sustainability-for embracing it.

Originality/value - This research is one of the few empirical academic works investigating the benefits of GBMs in the construction sector. The IRP method is a novel contribution to GBMs and construction research.

Keywords Benefits, Construction, Green business models, Interpretive ranking process, UK. Paper type Research paper

\section{Introduction}

With predictions of a rising global population and associated high resource use and environmental impacts, business as usual is not an option for a sustainable future (Bocken et al., 2014). AThe sustainable future requires a fundamental change in the purpose of business and virtually every aspect of how it is conducted (Beltramello et al., 2013). Green business models (GBMs) offer a potential approach to delivering the required change through re- 
considering value creation and capture logic (Sommer, 2012). A review of the literature relating to sustainability reveals that - with a few exceptions - there is no explicit definition of GBMs, this despite a growing interest in GBMs as a systematic approach to building the business case for environmental sustainability (Schaltegger et al., 2012). GBMs are developed from the-business models (BMs) literature (Sommer, 2012). Baden-Fuller \& Morgan (2010) provided three ways to use BMs: to describe and classify businesses; to form instruments of scientific investigation; and to act as practical tools for managers. Hence, GBMs can be used in the same manner. We used GBMs as a classifying tool to describe and expand our understanding of environmental sustainability within the construction sector. In other words, GBMs are used to understand existing environmental sustainability businesses and their benefits, in order to facilitate robust GBMs for the future of the construction sector.

Henriksen et al. (2012) provided a generic definition of the GBM: delivering products and services that offer an economically-viable environmental benefit by changing element-(s) of the existing BM. They used nine elements of the BM developed by Osterwalder; \& Pigneur; (2010), including: customer segment; customer relationship; channels; value proposition; key partners; key activities; key resources; cost structure; and revenue streams. The definition was based on both theoretical and empirical studies (mainly qualitative) conducted in the Nordic region to inform policy and practice about the role of GBMs in green transition. In addition, Henriksen et al. (2012) presented benefits of GBMs_as: environmental, innovation, and financial-benefits. Based on several industries, and with 41 business case studies, the study has contributed to GBM research at a generic level. This approach is similar to Sommer (2012)'s work that developed a framework to manage GBM transformations for different industries, based on seven case vignettes. Both studies aimed at developing GBMs that are widely applicable to different industries and conditions. However, this approach has limitations because it is not possible to empirically include a wide range of industries and a large number of companies, and hence may potentially lack some relevant details. Therefore, the current study differs from these studies by focusing on the construction sector as a specific case. In addition, the study is more concerned with benefits provided by GBMs to increase their uptake. A review of the literature shows that the topic of GBMs in the construction sector has been subject to little academic scrutiny (Al-Saleh \& Mahroum 2014).

The purpose is to empirically identify benefits of GBMs for the construction sector to build the business case for environmental sustainability and then to establish the relationship 
between benefits and elements of GBM by applying interpretive ranking process (IRP). IRP is generally used to establish the dominance relationship between two sets of variables - one to be ranked (elements of GBM) with reference to the other (benefits).

Following this introduction, the remainder of the paper is structured as follows: the first two sections of the paper (Sections 2 and 3) are conceptually oriented to establish important theoretical considerations for the construction sector and GBM elements respectively. These sections demonstrate the growing appreciation of GBMs in the construction discipline and show a lack of research in this niche area. Section 4 on methodology justifies the choice of the qualitative approach because of the exploratory nature of the current study and describes steps in the research process, including the selection process of research participants. The results are thus obtained by applying two different data analysis techniques: thematic analysis and IRP. Sections 5 and 6 present the empirical data and results: firstly, three categories of GBM benefits emerge by applying thematic analysis for the interviews. Secondly, an IRP model is constructed to rank the different GBM elements in order of importance in providing benefits for construction companies. The discussions in Section 7 show the novelty of linking GBMs elements and benefits through the IRP approach to build the business case for environmental sustainability for the construction sector. The conclusions in Section 8 highlight the added value to decision makers who are seeking relevant solutions to cope with market demands. The section also outlines limitations of the study and future research needs.

\section{Construction sector}

The construction sector worldwide is characterised by low cost rewards and short-term profit aspirations (Aho, 2013; Pekuri et al., 2014). Therefore, cost-cutting is seen as the only way to increase profits. The fear of additional costs associated with finding new ways of greening the sector has hindered environmental improvements (Lam et al., 2009; Sayce, Ellison, \& Parnell, 2007; Sodagar \& Fieldson, 2008). Empirical studies suggested that understanding the business case for environmental sustainability and discovery of new working methods will hasten environmental progress (Häkkinen \& Belloni 2011; Pitt et al., 2009). GBMs have the potential to contribute to these because they are concerned with the core logic of conducting a business based on green value creation and capture. This has been evident in the growing body of literature within green/sustainable construction dealing with GBMs. For example, Mokhlesian \& Holmén (2012) analysed green construction from the BM perspective. They 
argued that such a perspective facilitates better understanding of green construction processes and helps to separate green construction from "greenwashing". Their approach was particularly useful in explaining how and why construction firms can be successful, in terms of creating and capturing value when engaging in green construction. In a related vein, Aho (2013) suggested that the future of sustainable construction research is in BM transformation and he argued that the current research omitted this niche area. Both studies aimed at identifying the research gaps in studies that link green/sustainable construction and BMs/GBMs from a theoretical perspective. Recently, a few empirical studies have emerged in this area. Mahapatra et al. (2013) conducted a comparative study across Nordic countries to support BMs for full service energy efficiency renovations. Similarly, Al-Saleh \& Mahroum (2014) conducted a qualitative study to analyse GBMs that have emerged as a response to policies on energy efficiency. The above studies advocate economics and marketbased instruments as much stronger steering mechanisms towards green growth compared to legislation. However, none of these studies have investigated the benefits of GBMs. The current study thus contributes to this area by adopting generic elements of GBMs to be applied to the construction sector and by identifying benefits of GBMs empirically. Ahokangas \& Myllykoski (2014) analysed the general BM literature to understand the dynamics of BM creation and transformation as practices. They found that a business context to BMs has rarely been discussed, and. They_argued that the-contextual understanding will unlock BM potentials. We contribute to this area by applying GBMs to a specific business context: the construction sector.

\section{Green business model (GBM) elements}

As stated earlier, Henriksen et al. (2012) and Sommer (2012) have delivered comprehensive works on GBMs. Both works are based on BM definition and elements developed by Osterwalder (2004) to establish a common understanding of GBMs. Although Osterwalder's classification has been created from e-business, it has been used extensively for different purposes. In addition, this classification was the base of a BM canvas visualisation tool developed through online collaboration with different industries around the world (Osterwalder \& Pigneur, 2010). Henriksen et al. (2012) used the BM canvas, which includes nine elements, because it is internationally acknowledged as a practical tool to assist companies in aligning their activities by visualising potential trade-offs. However, Sommer (2012) went a step further by combining the BM elements of Osterwalder (2004) and Johnson 
et al. (2008). Consequently, Sommer (2012) developed five essential elements that are relevant for GBMs. These elements are adopted in this study for analysing the benefits of GBMs for two reasons: firstly, they are grounded on established previous research as presented above. Secondly, the interviewees agreed that these elements are essential and can explain the methodway of conducting green business in construction. The five elements are explained next.

The elements of the GBM can be defined from two value perspectives: value creation and value capture. Key Resources (KR) and Key Activity (KA) elements constitute the value creation perspective, while the Green Value Proposition (GVP) and Target Group (TG) elements constitute the value capture perspective. Value creation and value capture involve financial arrangements such as cost and revenues. Hence, a fifth element is added: Financial Logic (FL) (Sommer, 2012). The following subsections provide brief details of the GBM elements applied in this research.

\section{Green value proposition (GVP)}

Increasing expectations from the public at large in part drive the movement toward GVP. The GVP is mainly related to products and services offered by a particular company based upon their appeal to clients. Therefore, the GVP can be considered as a unique offering that a particular company delivers to its clients. Because this offer is unique, it can place the company in a relatively strong competitive position compared to its rivals (Frow \& Payne, 2011). For instance, a construction company may derive a reputational value from green services, reset the criteria that are most relevant to the client through environmental processes and practices and redefine the competition by helping clients to become green (Esty \& Winston, 2009). However, clients do not buy a product or service characteristics per se. Instead they buy the benefits a product or service brings. Consequently, it becomes essential for construction companies to highlight all the benefits associated with GVPs in order that the intended clients are able to capture economic value from their environmental products and services. According to Lindic and Silva (2011), the major problem of the value proposition in general is that companies often consider it in terms of what they offer to their clients, rather than what the clients really value. For this reason, the GVP is always to be seen in conjunction with the next element, the target group (Johnson at el., 2008). 


\section{Target group (TG)}

According to Sommer (2012), an attractive GVP alone is not enough for market success without a sound understanding of relevant target groups (TG). The TG presents the company's view on identifying and choosing relevant groups to which-that the GVP is intended to appeal to-(Osterwalder \& Pigneur, 2010). However, it is crucial for companies to understand the needs and preferences of the group that has been targeted. The ultimate goal of the TG identification is to promote GVP benefits and values; hence the potential clients/users must be fully aware of its distinctive advantages. In order to accomplish this goal, it is vital to recognise the values, needs, preferences, and behavioural choices of the specific TG (Zenker, 2009). Given the scepticism of many clients towards GBMs, it becomes crucial for companies to channel their resources and expertise to attract and convince targeted groups.

\section{Key activities (KA)}

The KA of a business consist of procedures and processes by which a given company adds value, procures resources, and produces products and services to a TG (Betz, 2002). In other words, KA refers to procedures and processes that are necessary to produce value and/or address the needs of clients or solve their problems. In addition, (Osterwalder \& Pigneur, 2010) defined KA as the most important activities that need to be performed to create customer value. The success of companies depends on managerial and operational activities that allow them to deliver value in a way thatey can successfully be repeated and result in increased sales. Examples of the managerial activities can be environmental planning, development, training and budgeting, while the operational activities can be manufacturing, sales, and services (Johnson, Christensen, \& Kagermann, 2008). GBM will need modification of management activities to accommodate their new elements, and it also influences the operational activities and processes are also influenced. $\mathrm{F}$, for example a given company may change from a product-based operation to a service-based operation.

\section{Key resources $(K R)$}

Key resources are available assets that are owned, controlled, and accessed by a company and can be categorised as tangible, intangible and human. Six main types of resources are adapted from Johnson et al. (2008) and discussed below: 
People, human assets or employees with their experience, training, relationships and insights are a crucial factor for any company. A GBM can greatly motivate employees by improving the company image. According to Steger (2006), environmental sustainability can be used to improve productivity by boosting both employee morale and the recruiting and retaining of high-quality, creative people.

Brand although not always the case, some green brands can be effective in commanding a higher price, increasing customer loyalty and boosting sales. Some companies are differentiating themselves as environmental leaders.

Knowledge can relate to any BM element of value. Examples include knowledge and information on customer preferences, or the company's environmental footprint. Knowledge is often dependent on IT, but is frequently associated with personal knowledge.

Technology can relate to processes and play a critical role in all clean/ green technology business models. It includes tradable know-how such as software licenses and the systems that a firm uses to run its businesses.

Physical assets can be a powerful source of competitive advantage and can include property and equipment.

Partnerships are a special and important case in that they can provide access to all the other resources listed above. Partnerships such as a deep relationship to a key partner or complicated supply chain can be argued to indicate a valuable resource in itself.

Some scholars suggest that the foundation of the KA construct is in the resource-based view (RBV) which regards each company as a bundle or resources (Al-Debei \& Avison, 2010; Barney, 2001). The RBV emphasises the strategic importance of resources and how these resources integrate to generate value for customers. This can eventually result in a sustainable competitive advantage to the company possessing the resources. However, possessing the resources is not enough to compete in the market ${ }_{2} ;$ these resources need also to be organised, combined, and configured in an appropriate manner (Hedman \& Kalling, 2003; Koruna, 2004). In fact, resources configuration demonstrates a company's capability to combine the various assets in a way that allows an efficient and effective roll-out of its products or services. Based on this discussion, we argue that the KR element of a GBM needs to represent company resources, their configuration, and the consequential core competencies. 


\section{Financial logic (FL)}

Financial logic (FL) is about the economic side of the GBM. It contains a cost structure and a revenue model, which together determine profitability for a given GBM (Osterwalder, 2004). According to Al-Debei and Avison (2010), the BM seems to be strongly associated with economic and financial arrangements and designs within companies. For many people, the concept is merely used to address financial arrangements including revenue generation. Nevertheless, this study suggests that the GBM is more comprehensive and that financial logic represents only one element of the concept. Many companies in GBMs realise substantial savings in the internal cost model by using input factors and energy more efficiently, by using environmentally-friendly substitutes and recycling waste, or by reducing cost related to emissions, like treatment costs and taxes (Lankoski, 2006). One important revenue model in the environmental sustainability context is the servicing model. This model aims to substitute selling physical products and material use with the provision of services. It helps the environment by facilitating a more efficient use of resources. The revenue comes from a steady stream of service charges rather than product sales (FORA, 2010; Sommer, 2012).

The GBM elements give a construction company a simple yet powerful tool to understand its current business model in order to systematically challenge the ways it does business and thereby enable the company to think differently and create new alternative GBMs. Furthermore, the GBM approach provides the decision-makers with tools based on the principle that systematic analysing and transforming of the GBM elements is one of the best routes to an optimal decision regarding environmental issues.

\section{Methodology}

According to Ding (2008), research methodology is mainly driven by the topic to be researched and the specific research questions. Therefore, in research design, the main issue is whether the researcher has made sensible decisions about the methods considering the aim of the study, the questions being examined, and the resources available, including time (Amaratunga et al., 2002). Due to the limited research available on GBMs both in management and construction disciplines, the current study is exploratory in nature. To achieve the aim of the study, seminal works were identified to make informed decisions about how to progress in the research. For example, Sommer (2012) carried out a comprehensive work on GBM transformations and conducted seven case studies to develop a 
management framework for such business models. He suggested that qualitative methods are appropriate to gain a better understanding of this new topic. Furthermore, Berns et al. (2009) started an annual survey for business for sustainability globally ${ }_{2}$ with an emphasis on BMs. However, before designing the survey, Berns et al. (2009) conducted detailed interviews with experts to inform the survey questions and key areas to be included. The findings of qualitative research are focused on revealing the qualities of phenomena rather than their static measurement. The qualitative method covers the subject of study comprehensively. It produces a wealth of detailed data on a small sample and the data collection is not restricted to pre-determined categories or themes (Hyde, 2000; Ko de and Norbert, 1998). The inherent flexibility of qualitative studies and their potential for revealing complexity was particularly relevant to this research, since the topic of investigation was complex in nature. In addition, qualitative data has often been advocated as the best approach for discovery and exploring a new area (Amaratunga et al., 2002). These features are aligned with the nature of the current research.

\section{Steps in the research process and methods}

There are three sequential steps deployed in this study to achieve the aim and objectives. The first step in the research process is to adopt general GBM elements. This step was mainly a deductive process of summarising main studies of GBMs (refer to the section of GBM elements above).

The second step is to empirically obtain approval of the choice of specific GBM elements adopted in the first step and to identify benefits of GBMs. For this, 19 semistructured interviews were conducted with experts from a varied sample within the UK construction sector and academia as detailed in Table 1. The selection criteria were as follows:

- Senior $\_$managers in the construction industry

- Relevant experience and knowledge in sustainability strategies and practices

- Relevant experience in business development and strategic plans

- A decision maker regarding sustainability issues, for example, being able to initiate and implement future plans

- Ideally, a sustainability manager, expert or officer. 
A research information sheet with an interview question guide was sent to the potential participants. The websites of all the participants' companies were reviewed in order to be familiar with their main activities and approach to environmental sustainability.

Contributors are classified by their expertise: Academic (A), Architect (AR), Consultant (CS), Contractor $(\mathrm{C})$, Other $(\mathrm{O})$ including property development and procurement and Client (CL).

Table 1. Interviewee profiles

As detailed in the table above, all the participants have considerable experience, with most of them having environment/sustainability within their job title. The participants were not given an explicit definition of GBMs but werethey presented with the five elements explained above. They were asked to comment on these elements and to add any additional elements if necessary. None of All the participants did not added additional elements and hence they approved the GBM elements presented in this research. Takingen these elements into consideration, the participants were asked the following question: What are the greatest benefits (tangible/intangible) to your company in addressing green issues? Please also list the economic benefits-as well, starting with the most important. In answering this question, the participants were referring to examples from their own experiences/-businesses. The examples were mostly framed using the elements presented to them. The value on this process was that participants were able to relate to these elements through sub-elements that expanded our understanding of main GBM elements within the construction context.

The results of the interviews were obtained by manually applying thematic analysis popularly known as qualitative content analysis (Chinyio \& Akintoye, 2008). Thematic analysis refers to an analytical approach involving examination of discussions to establish meanings and intentions (Fellows \& Liu, 2009). For example, interviewees have reported benefits of GBMs such as green credentials, positive impact on people, and attraction of staff and professional networks. The meaning (theme) extracted here was that these benefits are related to intangible benefits (reputation). Therefore, 'creditability/reputation' represents a benefit theme. Then the extracted 'creditability/reputation' benefit (theme) has been applied for the rest of the data to see if there was a similar explicit occurrence.

The third step provided an additional layer of the qualitative method to rank the different GBM elements with reference to the benefits identified through the data analysis. For this, the Interpretative Ranking process (IRP) was applied. 


\section{Interpretive ranking process (IRP)}

IRP is a ranking method that combines and uses the strength of both the logic choice process with the intuitive process of decision-making (Sushil, 2009). It builds on the strength of a pair-wise comparison approach which minimises the reasoning overload (Haleem et al., 2012). It also relies on an interpretative matrix as a basic tool and paired comparison of interpretation in the matrix to generate the ranking model. Sushil (2009) suggested that IRP is a more powerful method when compared to the existing logic methods such as the Analytic Hierarchy Process (AHP). The AHP method depends on an expert judgment about the importance of one element over another ene-in a pair-wise comparison along with its intensity. However, the interpretation of the importance and intensity of elements is left in an implicit manner with the expert and thereby the interpretive logic of a decision remains unclear to the implementer (Haleem et al., 2012; Sushil, 2009). On the other hand, the IRP method presents clearly the interpretive logic of the decision as the expert is supposed to spell out the interpretive logic for dominance of one element over the other for each pair-wise comparison (Haleem et al., 2012). This logic is usually documented on the knowledge base for future use by decision makers (Sushil, 2009). In addition, IRP does not require quantifying the degree of the dominance which is difficult to interpret and validate. Instead, it checks internal validity via the vector logic of the dominance relationships using a dominance system graph (Sushil, 2009). Furthermore, IRP ranks one set of variables with reference to another set of variables rather than ranking variables in an abstract sense. In this research, IRP is used to rank the GBM elements with reference to the benefits for construction businesses. This approach will give construction businesses a choice in developing GBMs by understanding which element will lead to which benefits. The ideal scenario is that construction businesses should appreciate the systematic nature of GBMs and that these elements are closely linked and affect the overall green value creation and capture process. IRP ranking gives a more practical approach for construction companies to follow and focuses on one element each time but the idea is that all these five elements are essential. In IRP, all the five elements are treated equally and there is no weight assigned to any oneelement.

Sushil (2009) stated that the interpretive approach to decision-making has been employed by different authors who use different constructs such as organisational culture, mental models, sense making, managerial frames, critical thinking and argument mapping. He also presented the steps of the basic IRP process as illustrated in Figure 1. 
Figure 1. Steps of IRP adapted from (Sushil, 2009)

-Despite the usefulness of the IRP method, it has limitations, as presented by Sushil (2009): it is subjective because it is based on interpretive process; it is difficult to be-validated by objective validation tests, and it is difficult to interpret a matrix of size beyond 10x10 because it will result ien a high number of paired comparison.

\section{Benefits of GBMs}

The participants believed and were convinced that GBMs offer benefits to companies and their clients. Despite the range of roles of those interviewed from the construction sector-whe were interviewed for this study, there was a consensus on the list of benefits offered by GBMs. To varying degrees, green companies are taking advantage of three key benefits of a focus on environmental sustainability: credibility/reputation benefits; financial benefits; and long-term viability benefits.

Figure 2. Benefits of GBMs

In Figure 2, the benefits of GBMs are organised by the researchers into three key benefits. These key benefits are highly influenced by the participants' answers and are summarised next. In other words, the bullet points are direct quotations from the interviewees.

\section{Credibility $/$ reputation benefits}

Interviewees agreed that the one of the major benefits of GBMs is intangible and is expressed in different terms such as credibility, reputation, brand, profile, track record, quality, attractiveness, and image. For example, CS1 stated that ${ }_{2}$ "The intangible benefits are very strong, stronger as a motivator than the tangible." Therefore, the intangible benefits are the major drivers of GBMs and most companies try to promote themselves on these bases. This was confirmed by the architects, $_{2}$ as AR1 reported that ${ }_{2}$ "The benefit to us is we slowly, maturely increase our reputation for being able to produce solutions that work, so in architecture reputation is everything really." In addition, AR2 indicated that reputation will lead to leadership on environmental issues as quoted next: "We want to be positioned in the
Formatted: Justified, Line spacing: 1.5 lines

Formatted: Justified 
marketplace as being a company that is responsible and is able to lead a team responsibly, particularly oin-the environmental issues." AR4 stated that their green brand has led to winning a green business award, where this has helped in ${ }_{2}$ "promoting ourselves as green architects." AR3 approached the intangible benefits from a slightly different angle where he stated: "reducing participation in unethical - unsustainable practices." According to AR3, the company started to make responsible decisions on running the business from reducing carbon footprint by considering alternative ways of transportation. It is worth noting that AR3 has explained that his company just started to consider environmental practices as part of the business as there is growing clients demand. The contractors indicated that there is a considerable demand for green buildings and hence it is important for contractors to demonstrate their ability in delivering such buildings. $\mathrm{C} 2$ stated that ${ }_{2}$ "We are a commercial organisation and inability to deliver a very green building is obviously damaging in the marketplace." For $\mathrm{C} 4$, the company was in a better position as they are considered one of the frontiers in environmental issues. $\mathrm{C} 4$ reported that ${ }_{2}$ "We do get sort of reputational things like our CEOs are invited to the green construction board and stuff like that which helps us in building connections and being in the right places." As result the company has the ability to influence wider industry decision- making regarding environmental issues. The clients also confirmed the reputational benefits of pursuing an environmental agenda. For example, CL1 from a local authority stated that ${ }_{2}$ "The city is the better place to live and work and that means people are attracted to it and that enhances its economic status. "CL3 confirmed that "The moral high ground, I think that is very important, your organisation is seen to be | responsible in the community, a moral and sort of credibility issue." CL4 stated that ${ }_{2}$ "The benefit to the company is in terms of leading the community." CL4 is from a local authority and hence it is important to lead the community bye example in environmental issues. This was achieved by developing a clear environmental strategy for the city where the local authority started to develop new ways of working and managing facilities. According to C2, the intangible benefits of GBMs cannot be underestimated and its positive impact on staff was clear. C2 stated that: "The staff involved in building green buildings generally have a sense of achievement." This has resulted in a-more commitment from the bottom and innovation aten the project site level that was also driven by Considerate Constructors Scheme scores. The Considerate Constructors Scheme was founded in 1997 by the construction industry in the UK to improve its image.

Although the interviewees have -agreed that intangible benefits of GBMs are 
predominant, they were able to demonstrate that intangible benefits have led to tangible benefits. They emphasised that intangible benefits are linked to two major tangible benefits: attraction of talented employees and increased demand. Typical comments were: "Image seen as industry/sector leader to attract like-minded staff and associates-" $\mathrm{C} 1$ from the contractors' group. $\mathrm{C} 3$ added that: "It [referring to reputation] helps attract and retain talent - people want to work with green businesses." CL2 and CL5 stated that green credentials lead to "employee satisfaction \& retention."

Examples of increased demand and new opportunities as a result of having green credentials were given by $\mathrm{C} 2$ and $\mathrm{C} 4 . \mathrm{C} 2$ stated that: "When you have that experience you are in a better position to bid for more work where environmental performance is demanded because you have the experience." In addition, C4 indicated that: "I think we had some examples where we specifically won some projects off the back of green or green was one of the reasons." He also added: "The benefit of having the reputation of doing those things lead to more work and we work on low margins so we need a lot of revenue, a lot of money through our books every year, and the market is very competitive." $\mathrm{O} 2$ has a similar opinion: "We need to demonstrate that we have an understanding of the issues, the technology, the services, the work, that contractors will deliver to inspire our clients and let them buy them from us rather than somebody else, so there are real economic benefits for us from promoting being able to provide environmental technology and services." According to $\mathrm{O} 2$, their green credential was a differentiator in the market and they were able to charge an-extra for their services. A detailed discussion about the direct financial benefits of GBMs is presented next.

\section{Financial benefits}

The participants are broadly categorized into providers (supply) and clients (demand) ${ }^{4}$ companies but the majority is from the supply side, as presented in Table 1. The question of financial/economic benefits aimed to capture direct benefits received by both the provider companies and by the client companies. Surprisingly, the answers were directed to highlight clients' benefits and all the participants agreed that financial benefits are mainly aimed at clients. More precisely, the financial benefits go to the end-users or actual occupiers of the building with. However, the provider companies were able to-providinge their financial benefits.

Clients mainly benefit from lower costs of building operation; a. As expected, the energy 
cost is the major driver of operational costs with less focus on water cost. Hence, all the client participants from the clients have-stated that they started to consider whole life cycle costing of their buildings to be able to demonstrate the-cost savings they receive. For example, CL1 indicated that: "The business case is pretty straight forward really if you start off assuming that anything you are doing to deliver is a saving in cost by reducing the number of buildings you have." CL2 added that: "Reducing life-cycle costs for the individual responsible for the long term running costs of the building." CL3 elaborated by stating: "I think economic benefits cover the whole range of things whether it be- saving money because, for instance, you use less energy, or because you cut your emissions and therefore save on taxes. There is also obviously a tax benefit for being more green." It is worth noting that the clients interviewed are from organizations with large building stock such as local authorities and universities, hence they are responsible for the long-term running/maintenance of the buildings. This means that it is easier for those clients to see the financial benefits and the motivation is already there. However, clients who do not maintain the ownership of the buildings may not be as motivated as the ones who do, unless there are other incentives in place. As mentioned earlier in this section, interviewees from the provider companies have also reported financial benefits for their clients. AR1 indicated that: "Clients will benefit from whole life costing in reducing their carbon or their energy requirements, whether they realize it or not." C3 confirmed AR1's statement: "The benefit here is for the occupier of the building so they have a cheaper energy and utility cost over the whole life without being exposed to rising gas and electric costs. So the main benefit is for the end users of a building, otherwise they might not want to spend that additional cost." The statement reported by C3 indicated that additional capital costs are needed but he suggested that he generally uses the whole life cycle costing as a way to prove the business case for clients. AR2 raised an interesting point where he stated that: "Clients being able to portray their buildings as competitive because of their green features certainly can be used as a sales vehicle for their buildings." The idea of using these buildings as a marketing tool may motivate more clients to uptake GBMs even if they do not maintain a long-term ownership of the building. Hence, green certification/accreditation may have a major role to play as a marketing/promotion tool.

For provider companies, the benefits reported can be mainly divided into two broad categories: cost savings on running the business and new market opportunities. Major cost savings reported are similar to the ones reported for clients where benefits are gained from lower running costs. A typical comment came from $\mathrm{C} 4$ : "We do make cost savings, 
absolutely. We invested money in some of our key offices and we start to get the savings back now. I think we invested more than 1 million at our head office and that should make savings , I think in the region of $100 \mathrm{~K} /$ year on electricity and gas -- it is a big saving." Another area of cost savings focuses on finding new ways of running the business. An example of this, given by CS2, is -online meetings. AR3 confirmed that: "We are able to reduce overheads/fuel costs" by implementing green measures such as hybrid cars and reducing waste, particularly paper waste.

New market opportunities have emerged from existing clients with new demands, especially clients from public bodies. For example, CS2 stated that: " $4 \%$ of our turnover came directly from environmental services. From the service side we know we can get more work, which is good." CS2 was mainly referring to existing public clients were there have been increased demands on environmental services. A1 also confirmed that: "In some cases companies with sustainability strategies have been more competitive, particularly when bidding for public sector contracts." For AR4, it represents, "A niche market - new market, it was not here before." AR4 focuses on environmental services to bring more work and hence increase their bottom-line. $\mathrm{C} 3$ confirmed the point above by stating that: "The very tangible benefit is winning work, improving turnover and therefore improving profit." $\mathrm{O} 2$ added that: "One of the greatest benefits to our business is the impact ontə the bottom line." Some of the participants focused on competitive advantage as a way to access new opportunities. For example, C3 indicated that: "We see it [referring to green services] as a strategic differentiator: environmental or green or sustainable - however you badge it - if you do it well and sell it, it improves your competitiveness." The academics have a slightly different perspective on financial benefits for provider companies, where they discussed the insurance requirements in the future where sustainability will be a major key risk indicator for insurers. A1 stated that: "Getting insurance cover it is going to be very important in the |future; the more sustainable you are the less of a risk you are-for financing and funding." This may be an area to be considered as a market driver for GBMs and for engaging financial institutions in the debate for better incentives. Having presented the financial benefits of GBMs, the next section deals with the final benefit: long-term viability.

\section{Long-term viability benefits}

Although long-term viability benefits are not highlighted explicitly by most of the participants, all of them have implied in some form or another a long-term view on green 
issues. The results presented in this section are based on explicit opinions of some, or the interviewees. CS1 believed that GBMs are a means to sustain the business and it is important to deal with them from the long-term perspective to be able to deliver them. He stated that: "In 10 years time I am here and you are not because I was looking ahead and I was making changes now. So investing in the future is fundamental." These types of businesses will become more attractive and will grow as a result of gettingbecoming ahead of the game. AR1 added that: "It is about economic viability or long-term viability ethos." O1 supported the same view, as he indicated that the lack of GBMs within the sector will lead to disappearance of businesses. O1 stated that: "If you do not keep up to speed with environmental issues, you will be a dinosaur, you will be extinct." Some of the participants including A1, AR4, O1, CL2, and CL5 reported that GBMs tend to improve the relations between the demand and supply sides, hence indicating a long-term loyalty from clients that ensures a steady revenue stream that will help supply companies to survive in the market.

Innovation is seen by the participants as a main tool to ensure long-term viability. From their experience, GBMs enhance innovation capacity in the business process, in product and services, productivity, and the market. Most innovative ideas have come as a result of improving environmental performance. For example, light sensors to improve efficiency and reduce energy consumption. Furthermore, green companies have a good relationship with their stakeholders. This can provide sustainable revenues and staying power in the market.

In the next section, we apply IRP to rank the various GBM elements with reference to each benefit area presented above. This ranking will help in understanding the influence of each element when it comes to benefits for companies. It will also help managers to make an informed decision about investment plans on GBM elements.

\section{IRP for GBM elements and benefits}

In the following subsection, IRP is used to assess the relative impacts- of the various benefit areas in construction businesses.

\section{Identifying GBM elements to be ranked with reference to benefits}

As presented in Figure 1, the first step in the ranking process is to identify two sets of variables. One set is comprised of variables that are to be ranked and the other set is 
comprised of reference variables. In this research, the ranking set consists of 'GBM elements' and the reference set consists of 'benefits' for companies, as shown in Table 2 below.

Table 2. Variables of GBM elements and benefit areas

In the Table above, there are five GBM elements: namely, GVP, TG, KA, KR, and FL and three benefits: namely, B1, B2, and B3. The issue is ranking the five GBM elements with respect to their influence on various benefits to companies.

\section{Establishing the contextual relationship between GBM elements and benefits}

Once the variables are identified as in the previous step, the next step is to clarify the contextual relationship among -them. In the case of this study, the contextual relationship is the 'influence of GBM elements in different benefit areas. The elements having more influence are ranked higher. These relationships have been identified by the participants based on their expertise.

\section{Developing a cross-interaction matrix of GBM elements and benefits}

A cross-interaction matrix questions the existence of a relationship between each GBM element and each benefit area. A binary matrix can represent the cross-interaction of variables with ' 1 ' indicating a relationship between the pair of variables and ' 0 ' indicating no relationship. Table 3 below presents the cross-interaction matrix.

Table 3. Cross-interaction matrix (binary matrix)

\section{Interpretation of interactions}

The cross-interaction- binary matrix is converted into a cross-interaction-interpretive matrix by interpreting all the interactions with entry ' 1 ' in terms of the contextual relationship. For example, (GVP, B1) is interpreted as 'GVP will enhance companies' reputation' as shown in Table 4. As mentioned earlier, these relationships and interpretations were obtained from the interviews conducted with the construction sector practitioners. The interpretive matrix becomes the essential data for comparison, for the purpose of ranking the variables.

Table 4. Interpretive matrix 


\section{Pair-wise comparison}

The interpretive matrix is used as a foundation to match GBM elements (ranking variables) ${ }^{4}$ with the benefit areas (reference variables), pairwise. For example, the GBM element GVP is compared with the GBM element TG with reference to various benefits, B1, B2, and B3 respectively and the interpretive logic of the dominating interaction between GVP and TG with reference to the various benefit areas which are recorded in the knowledge base, and presented in Table 5. It is worth nothing that the GBM elements (ranking variables) are not directly compared, but rather their interaction with reference to the benefit (reference variables) is compared. All the dominating interactions are summarised in the dominating interaction matrix, as shown in Table 6.

Table 5. Interpretive logic - Knowledge base - ranking of GBM elements with reference to benefits

Table 6. Dominance interaction matrix

\section{Developing the dominance matrix}

The numbers of dominating interactions are summarised in the form of a dominance matrix, dominates or is being dominated by another GBM element (ranking variable). In Table 7 below, the dominance matrix of the GBM element with reference to the benefits for businesses is given. The sum of rows gives the total number of cases in which the respective GBM element dominates all other GBM elements. The sum of a column indicates the total number of cases in which a particular GBM element is being dominated by all other GBM elements. The difference of number dominating in column ' $\mathrm{D}$ ' and the corresponding number being dominated in row ' $\mathrm{B}$ ' gives the net dominance for a GBM element (D - B). The GBM element having the highest net positive dominance in the maximum number of benefits is ranked 1, followed by the next lowest and so on. For example, in Table 7, the KR had highest net positive dominance and was ranked 1, the GVP and FL were ranked 2 with a net positive dominance of 2 , the TG was ranked 3 with a net negative dominance of -3 , and the KA was ranked 4 with a net negative dominance of -7 . The sum of all net dominances for various GBM elements should eome out to-be zero, $(2-3-7+6+2=0)$, as presented in the table below. 
This can be used as a cross-check to validate the dominance relationships (Sushil, 2009).

Table 7. Dominance matrix - Ranking of GBM elements with reference to benefits

\section{Interpretive ranking model}

The interpretive ranking model displays the final ranks of the GBM elements diagrammatically. This model displays the final ranks of the ranking variables. Figure 2 illustrates the ranks of GBM elements with reference to various benefit areas. The arrows in the diagram represent the benefits in the cases where a particular GBM element dominates the other GBM elements. For all the GBM elements, the numbers dominating and numbers being dominated are summarised within brackets.

Figure 3. Interpretive ranking model for GBM elements with reference to benefits

The ranking model shown in the Figure above interpreted the influence and dominance of various GBM elements on the benefit areas. This model is helpful in developing GBMs which enhance the benefit areas that comprise the ultimate goal for construction companies.

According to Sushil (2009), the validation of model structure is related to reviewing the ranking and reference variables. As stated above, the GBM elements (ranking variables) are adopted from established literature and agreed by the participants. The benefits (reference variables) are emerged from the thematic analysis of the data and are crossed_checked with the available literature. Another validation is related to the interpretation of interactions. The interpretive -matrix in Table 4 was based on the participants' answers according tofrem their expertise.

\section{Discussions}

From the IRP model in Figure 3, the KR is shown to be an important GBM element that ${ }^{+}$ influences all benefit areas including: credibility/reputation (B1), financial benefits (B2), and long-term viability (B3). When companies decide to develop GBMs or offer GVPs, they usually modify and acquire key assets in doing so. These assets or resources will become essential in achieving the aforementioned benefits. The importance of resources is also supported in the literature and is better known as RBV (Al-Debei \& Avison, 2010). The RBV 
suggests that a company can use its resources and capabilities to create competitive advantage which ultimately will result in superior value creation. It also gives the resources a major role in helping companies to achieve higher organisational performance (Kraaijenbrink, Spender, \& Groen, 2010). The difference between the RBV and the KR of GBM is that the former focuses on the internal resources only while the latter includes internal and external resources. Therefore, it can be argued that the KR has a more inclusive nature and at the same time represents only one element of the GBM, although it proves to be more influential in benefits gained for businesses. The inclusive nature of the KR can facilitate alliance and partnership relationships that are core themes in the construction research agenda (Fiedler and Deegan, 2007; Khalfan et al., 2008). Companies in partnership can come together and access different resources that may be difficult to own and control internally. Another support for resources, and particularly human resources, was found in the recently published Construction Strategy 2025 (HMG, 2013). The strategy begins with a clear vision of where UK construction will be in 2025 and positions people at the centre of the debate, with the aim of increasing workforce capability in the construction sector-(HMG, 2013). For construction companies, it is important to look at the KR needed for GBMs as a prerequisite to gaining various benefits, rather than a roadblock. It is also much more feasible for companies to exploit opportunities using existing resources in a new way rather than trying to acquire new resources for each different opportunity. For example, CasadesusMasanell and Ricart (2011) argued that successful BMs are self-reinforcing by accumulating resources. The leaders of these BMs gathered those resources not by buying them, but by making smart choices such as reputation, asset utilisation, and production experience. These findings may motivate more construction companies to transform their BMs into green.

The GVP and FL were at Rank 2 on influencing benefits gains for businesses. The construction literature emphasised the benefit of offering GVP such as innovation opportunities, reducing life-cycle cost, efficiency, increased business productivity and achieving long-term profits (Alec et al., 2012; Bartlett \& Howard, 2000; Vatalis et al., 2011). The interpretive ranking model illustrated in Figure 2 above partially agreed with these findings, where it showed that the GVP has influenced all benefit areas (B1, B2, and B3). However, the model did not position the GVP at Rank 1 as one would expect, instead it positioned the KR first, as explained above. The model's findings signified the importance of offering the GVP but also suggested that it should not be expected to benefit businesses directly but instead it will be the KR that is developed to offer the GVP. Consequently, 
offering GVPs can be a means towards acquiring and developing valuable KR to eventually benefit businesses and at the same time internalise GBMs. The FL appeared to influence only two benefits (B2 and B3) because it focuses on cost and pricing which are major contributors to profit making and viability of businesses. A well designed FL can lead to sustained businesses and new opportunities and eventually to tangible benefits. However, the construction sector has been hard hit by the economic downturn which has affected the FL of the sector (Dadhich et al., 2015). Therefore, it becomes crucial to create conditions such as access to finance and payment practices to enable the sector to thrive and invest in people and technology - KR (Häkkinen \& Belloni, 2011).

The TG was ranked as the third most important element influencing benefit areas for businesses. It influenced only one benefit (B2) which came as a surprise because clients/stakeholders (TG) have been in the spotlight for a long time and have been blamed for the lack of impetus- of the green movement in the sector (Häkkinen \& Belloni, 2011; Opoku \& Ahmed, 2014; Pitt et al., 2009). The influence of the TG on financial benefits (B2) stems from the power of clients in buying the GVP and hence improving sales returns for companies. However, the TG appeared to have less influence on the long-term viability benefits and it can be significant for companies to realise that the viability of their businesses depends mainly on internal rather than external elements. This implies that construction companies should take full responsibility in enhancing and sustaining their businesses by securing appropriate resources, designing finance, and offering the GVP. To increase the TG's influence on businesses viability, it might be useful to deal with clients as 'the stakeholder' rather than 'the paying customer' (Walker, 2000). The quality management (ISO 14000 dedicated to environmental management issues) suggested that stakeholders can provide valuable information about how they are affected by the GVP and can co-operate with those delivering the output.

The KA is positioned in the final rank (Rank 4) and appeared to have the least influence on benefit areas compared to the rest of the GBM elements. It mainly influenced the reputation benefits (B1) which can be due to the direct link between how companies perform and their reputation in doing so. For example, a construction company which has a GBM will perform its activities in a more environmentally friendly manner by, for instance, generating less waste, using renewable sources, and consuming less energy. The implication of these findings might be of interest to construction companies because it seems that the core 
business (KA) does not have a major impact on benefits. In other words, a construction company may perform any KA as long as it adheres to environmental requirements and still gains various benefits through the rest of the GBM elements such as KR, GVP, and FL. At the same time, it is essential to consider the GMB elements as a whole and well reinforced system (Pekuri, Pekuri \& -Haapasalo 2013).

Our contribution is that we presented five elements of GBM that can be used as an analytical* tool to make sense of the real world of environmental practices within the construction sector. We also defined GBMs as the logic of green value creation and capture. Adopting these views, we are able to identify empirically the benefits of GBMs and hence building the business case for environmental sustainability. Building the business case is considered one of the most promising ways to facilitate green growth and a low carbon future (Dadhich et al., 2015; Tan et al., 2015). Applying IRP to rank the GBM elements with reference to the benefits, has given the construction businesses some structure and better understanding of how these elements will benefit them and their clients. IRP was also appropriate to this analysis because it deals with all the elements equally $y_{2}$. This important for the systematic nature of GBMs.

\section{Conclusions}

The purpose of this research was to empirically identify benefits of GBMs for the construction sector, then to rank the importance of GBM elements with reference to benefits to build the business case for environmental sustainability. To achieve the purpose, three sequential steps of research methods are followed. Firstly, a literature review to identify GBMs and their elements. Five essential elements are adopted based on inclusive conceptual and empirical research on GBMs: GVP; TG; KA; KR; and FL. Secondly, semi-structured interviews with 19 participants from the UK construction sector to identify benefits of GBMs. The participants approved the five elements to establish a common understanding of GBMs. Based on this understanding, they were able to identify benefits offered by GBMs. Three major themes of benefits emerged from the analysis: credibility benefits; financial benefits; and long-term viability benefits. Thirdly, IRP was used as an additional layer of qualitative analysis. In the IRP ranking, KR achieved the top rank and influenced all the benefit areas. For construction companies, it is important to look at the KR needed for GBMs as a prerequisite to various benefits, rather than as an obstacle to obtaining them. This result may encourage companies to view GBMs as a business opportunity rather than a threat. It is worth 
noting that this result also encourages managers to develop and obtain the KR, but excludes approaches to accomplish this as they are beyond the scope of the current study. The IRP method is a novel contribution to GBMs and construction research. Despite the original contributions of this study, it has some limitations. First, there are no adequate quantitative empirical data available yet to support or reject the qualitative extrapolations that have been presented in this study. Second, the research focused primarily on the UK construction sector and relied on empirical data from the UK only.

To better understand GBMs and the associated benefits, research on specific GBMs such as performance-based and low carbon models and their direct benefits would be fruitful.

Although GBMs are new in the construction discipline, this research, as far as can be established, is one of the few empirical academic works introducing GBMs and their benefits in the construction context. 
Aho, I. (2013). Value-added business models: Linking professionalism and delivery of sustainability. Building Research \& Information, 41(1), 110-114.

Ahokangas, P. \& Myllykoski, J. (2014) The practice of creating and transforming a business model, Journal of Business Models, Vol. 2, No. 1, pp. 6-18.

Al-Debei, M. M., \& Avison, D. (2010). Developing a unified framework of the business model concept. European Journal of Information Systems, 19(3), 359-376.

Al-Saleh, Y., \& Mahroum, S., A (2014) Critical review of the interplay between policy instruments and business models: Greening the built environment a case in point, Journal of Cleaner Production.

Alec, S., Adam, N., Jarrod, R., \& Nishani, H. (2012). Life cycle cost analysis: a case study of Lincoln on the Lake. Journal of Engineering, Design and Technology, 10(2), 228-254.

Amaratunga, D., Baldry, D., Sarshar, M., \& Newton, R. (2002). Quantitative and qualitative research in the built environment: application of "mixed" research approach. Work Study, 51(1), 17-31.

Baden-Fuller, C., \& Morgan, M.S. (2010) Business models as model. Long Range Planning $43,156-171$

Bartlett, E., \& Howard, N. (2000). Informing the decision makers on the cost and value of green building. Building Research \& Information, 28(5-6), 315-324.

Beltramello, A., Haie-Fayle, L., Pilat, D. ( 2013) Why New Business Models Matter for Green Growth. OECD Publishing, Paris.

Berns, M., Townend, A., Zayna, K., Balagopal, B., Reeves, M., Hopkins. M. \& Kruschwitz, N. (2009) The business of sustainability. Findings and insights from the first annual business of sustainability survey and the global thought leaders research project. MIT Sloan Management Review.

Betz, F. (2002). Strategic business models. Engineering Management Journal-Rolla-, 14(1), 21-28. 
Bocken, N.M.P., Short, S.W., Rana, P., \& Evans, S. (2014) A literature and practice review to develop sustainable business model archetypes. Journal of Cleaner Production, 65, $42-56$.

Chinyio, E. A., \& Akintoye, A. (2008). Practical approaches for engaging stakeholders: findings from the UK. Construction Management and Economics, 26(6), 591-599.

Dadhich, P., Genovese, A., Kumar, N., \& Acquaye, A. (2015). Developing sustainable supply chains in the UK construction industry: A case study. International Journal of Production Economics, 164, 271-284.

Esty, D. C., \& Winston, A. S. (2009). Green to gold: How smart companies use environmental strategy to innovate, create value, and build competitive advantage: John Wiley \& Sons Inc.

Fellows, R. F., \& Liu, A. M. (2009). Research methods for construction: John Wiley \& Sons.

Fiedler, T., \& Deegan, C. (2007). Motivations for environmental collaboration within the building and construction industry. Managerial Auditing Journal, 22(4), 410-441.

FORA. (2010). Green business models in the Nordic region: A key to promote sustainable growth. Copenhagen.

Frow, P., \& Payne, A. (2011). A stakeholder perspective of the value proposition concept. European Journal of Marketing, 45(1/2), 223-240.

Häkkinen, T., and Belloni, K. (2011) Barriers and drivers for sustainable building, Building Research \& Information, 39:3, 239-255.

Haleem, A., Sushil, Qadri, M. A., \& Kumar, S. (2012). Analysis of critical success factors of world-class manufacturing practices: an application of interpretative structural modelling and interpretative ranking process. Production Planning \& Control, 23(1011), $722-734$.

Hedman, J., \& Kalling, T. (2003). The business model concept: theoretical underpinnings and empirical illustrations. European Journal of Information Systems, 12(1), 49-59.

Henriksen, K., Bjerre, M., Almasi, A. M., \& Damgaard-Grann, E. (2012). Green Business Model Innovation: Conceptualization report. Nordic Innovation Publication Oslo, Norway. 
HM Government. (2013). Construction 2025: Industrial strategy for construction. GOV.UK.

Hyde, K. F. (2000). Recognising deductive processes in qualitative research. Qualitative Market Research: An International Journal, 3(2), 82-90.

Johnson, M. W., Christensen, C. M., \& Kagermann, H. (2008). Reinventing your business model. Harvard business review, 86(12), 57-68.

Khalfan, M. M., McDermott, P., Li, X., \& Arif, M. (2008). The integration of suppliers and manufacturers within construction supply chains through innovative procurement strategies. International Journal of Value Chain Management, 2(3), 358-370.

Ko de, R., \& Norbert, S. (1998). Positioning qualitative market research: reflections from theory and practice. Qualitative Market Research: An International Journal, 1(1), 714.

Koruna, S. (2004). Leveraging knowledge assets: combinative capabilities-theory and practice. R\&D Management, 34(5), 505-516.

Kraaijenbrink, J., Spender, J.-C., \& Groen, A. J. (2010). The resource-based view: a review and assessment of its critiques. Journal of management, 36(1), 349-372.

Krämer, A., \& Herrndorf, M. (2012). Policy measures to support inclusive and green business models, United Nations, Global Compact.

Lam, P.T.I., Chan, E.H.W., Chau, C.K., Poon, C.S. and Chun, K.P. (2009) Integrating green specifications in construction and overcoming barriers in their use. Journal of Professional Issues in Engineering Education and Practice, 135(4), 142-152.

Lankoski, L. (2006). Environmental and Economic Performance The Basic Links. Schaltegger, S. and Wagner, M. Managing the Business Case for Sustainability Sheffield: Greenleaf Publishing, 32-46.

Lindic, J., \& Silva, C. M. d. (2011). Value proposition as a catalyst for a customer focused innovation. Management Decision, 49(10), 1694-1708.

Mahapatra, K., Gustavsson, L., Haavik, T., Aabrekk, S., Svendsen, S., Vanhoutteghem, L., Satu Paiho, S., \& Ala-Juusela, M. (2013) Business models for full service energy renovation of single-family houses in Nordic countries, Applied Energy, 112,15581565. 
Mokhlesian, S., \& Holmén, M. (2012). Business model changes and green construction processes. Construction Management and Economics, 30(9), 761-775.

Opoku, A., \& Ahmed, V. (2014). Embracing sustainability practices in UK construction organizations: Challenges facing intra-organizational leadership. Built Environment Project and Asset Management, 4(1), 90-107.

Osterwalder, A. (2004). The business model ontology: A proposition in a design science approach. Academic Dissertation, Universite de Lausanne, Ecole des Hautes Etudes Commerciales, 2 .

Osterwalder, A., \& Pigneur, Y. (2010). Business model generation: a handbook for visionaries, game changers, and challengers: Wiley.

Pekuri, A., Pekuri, L., \& Haapasalo, H. (2013). The role of business models in Finnish construction companies. Australasian Journal of Construction Economics and Building, The, 13(3), 13.

Pekuri, A., Suvanto, M., Haapasalo, H., \& Pekuri, L. (2014). Managing value creation: the business model approach in construction. International Journal of Business Innovation and Research, 8(1), 36-51.

Pitt, M., Tucker, M., Riley, M., \& Longden, J. (2009). Towards sustainable construction: promotion and best practices. Construction Innovation: Information, Process, Management, 9(2), 201-224.

Sayce, S., Ellison, L. and Parnell, P. (2007) Understanding investment drivers for UK sustainable property. Building Research \& Information, 35, 629-643.

Schaltegger, S., Lüdeke-Freund, F., Hansen, E. (2012) Business cases for sustainability: The role of business model innovation for corporate sustainability. Int. J. Innovat. Sustain. Dev. $6(2)$.

Sodagar, B. and Fieldson, R. (2008) Towards a sustainable construction practice. Construction Information Quarterly,10, 101-108.

Sommer, A. (2012). Managing green business model transformations. Verlag Berlin Heidelberg: Springer. 
Steger, U. (2006). Building a business case for corporate sustainability. Schaltegger, Stefan; Wagner, Marcus: Managing the Business Case of Sustainability. The Integration of Social, Environmental and Economic Performance. Greenleaf-Publishing. Sheffield. S, 412-443.

Sushil. (2009). Interpretive Ranking Process. Global Journal of Flexible Systems Management, 10(4), 1-10.

Tan, Y., Ochoa, J. J., Langston, C., \& Shen, L. (2015). An empirical study on the relationship between sustainability performance and business competitiveness of international construction contractors. Journal of Cleaner Production, 93, 273-278.

Vatalis, K. I., Manoliadis, O. G., \& Charalampides, G. (2011). Assessment of the economic benefits from sustainable construction in Greece. International Journal of Sustainable Development \& World Ecology, 18(5), 377-383.

Walker, D. H. (2000). Client/customer or stakeholder focus? ISO 14000 EMS as a construction industry case study. The TQM Magazine, 12(1), 18-26.

Zenker, S. (2009). Who's your target? The creative class as a target group for place branding. Journal of Place Management and Development, 2(1), 23-32. 
Table 1. Interviewee profiles

\begin{tabular}{|c|c|c|c|c|c|}
\hline No & ID & Type of business & Job title & $\begin{array}{c}\text { Years of } \\
\text { experience }\end{array}$ & $\begin{array}{c}\text { Size of } \\
\text { company }\end{array}$ \\
\hline 1 & $\mathrm{~A} 1$ & University & Professor & 15 & 2500 \\
\hline 2 & A2 & University & Professor & 15 & 2500 \\
\hline 4 & AR1 & Architects & Architect \& director & 20 & 6 \\
\hline 5 & AR2 & Architects & Associate architect & 20 & 6 \\
\hline 6 & AR3 & Architects & Associate architect & 14 & 110 \\
\hline 7 & AR4 & Architects & $\begin{array}{l}\text { Associate director } \\
\text { architect }\end{array}$ & 9 & 12 \\
\hline 3 & $\mathrm{CS} 1$ & Consultancy & Freelance consultant & 36 & 1 \\
\hline 8 & $\mathrm{CS} 2$ & $\begin{array}{l}\text { Property and } \\
\text { construction } \\
\text { consultancy }\end{array}$ & Environmental manager & 5 & 350 \\
\hline 9 & $\mathrm{C} 1$ & Contractors & Director & 50 & 50 \\
\hline 10 & $\mathrm{C} 2$ & Contractors & Sustainability manager & 17 & 800 \\
\hline 11 & $\mathrm{C} 3$ & Contractors & $\begin{array}{l}\text { Senior sustainability } \\
\text { manager }\end{array}$ & 14 & 5000 \\
\hline 12 & $\mathrm{C} 4$ & Contractors & $\begin{array}{l}\text { Senior sustainability } \\
\text { manager }\end{array}$ & 12 & 6000 \\
\hline 13 & $\mathrm{O} 1$ & $\begin{array}{l}\text { Others - Property } \\
\text { development }\end{array}$ & Construction director & 36 & 16 \\
\hline 14 & $\mathrm{O} 2$ & Others - Procurements & Sustainability manager & 8 & 50 \\
\hline 15 & CL1 & $\begin{array}{l}\text { Clients/ Local } \\
\text { Authority }\end{array}$ & $\begin{array}{l}\text { Capital programme } \\
\text { director }\end{array}$ & 40 & 10.000 \\
\hline 16 & CL2 & Clients/ University & $\begin{array}{l}\text { Associate director } \\
\text { operations \& facilities }\end{array}$ & 36 & 260 \\
\hline 17 & CL3 & Clients/ University & Building surveyor & 20 & 245 \\
\hline 18 & CL4 & $\begin{array}{l}\text { Clients/Local } \\
\text { Authority }\end{array}$ & $\begin{array}{l}\text { Operational facilities } \\
\text { manager }\end{array}$ & 15 & 10.000 \\
\hline 19 & CL5 & Clients/ University & $\begin{array}{l}\text { Environmental \& } \\
\text { sustainability officer }\end{array}$ & 10 & 250 \\
\hline
\end{tabular}


Table 2. Variables of GBM elements and benefit areas

\begin{tabular}{ll}
\hline Components & Variables \\
\hline & GVP - Green value proposition \\
& TG - Target group of GBMs \\
GBM elements & KA - Key activities for GBMs \\
& KR - Key resources for GBMs \\
& FL - Financial logic of GBMs \\
& B1 - Credibility/ Reputation \\
Benefit areas & B2 - Financial \\
& B3 - Long-term viability \\
\hline
\end{tabular}

Table 3. Cross-interaction matrix (binary matrix)

\begin{tabular}{cccc}
\hline & B1 & B2 & B3 \\
\hline GVP & 1 & 1 & 1 \\
TG & 0 & 1 & 0 \\
KA & 1 & 1 & 0 \\
KR & 1 & 1 & 1 \\
FL & 0 & 1 & 1 \\
\hline
\end{tabular}

30

33

34

35

36

37

38

39

40

41

42

43

44

45

46

47

48

49

50

51

52

53

54

55

56

57

58

59 
Table 4. Interpretive matrix

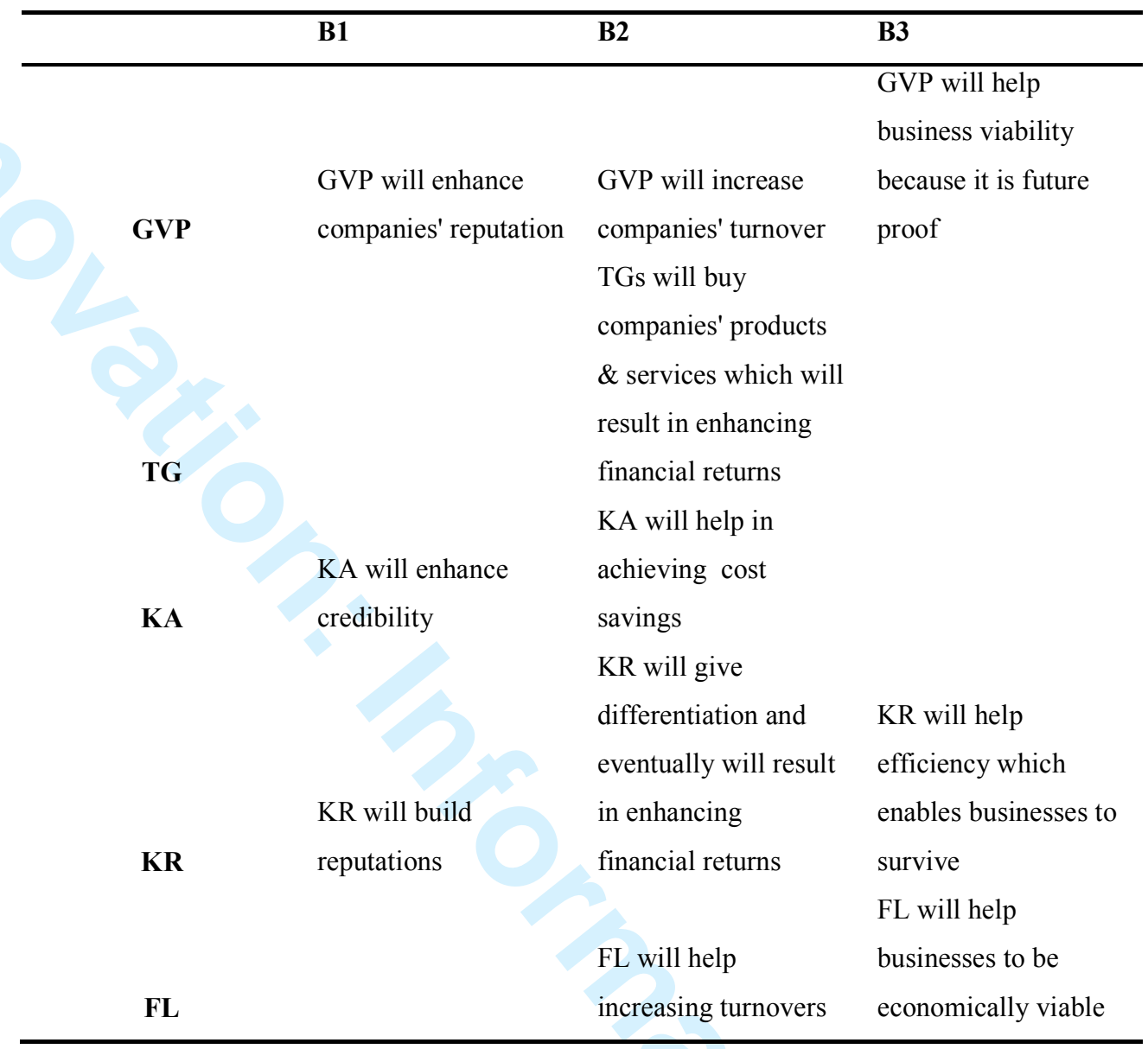


Table 5. Interpretive logic - Knowledge base - ranking of GBM elements with reference to benefits

\begin{tabular}{|c|c|c|}
\hline Paired comparison & $\begin{array}{l}\text { Interaction with } \\
\text { benefit }\end{array}$ & Interpretive logic \\
\hline \multirow[t]{2}{*}{ GVP dominating TG } & B1 & TG i has no direct impact \\
\hline & B3 & TG has no direct impact \\
\hline \multirow[t]{3}{*}{ GVP dominating KA } & B1 & $\begin{array}{l}\text { GVP has more influence than KA in enhancing } \\
\text { companies' reputation }\end{array}$ \\
\hline & B2 & GVP is more important in generating revenues \\
\hline & B3 & KA has no direct impact \\
\hline GVP dominating KR & B2 & $\begin{array}{l}\text { GVP contributes more to generating sales and } \\
\text { revenues compared to KR }\end{array}$ \\
\hline GVP dominating FL & B1 & FL has no direct impact \\
\hline TG dominating GVP/ KA/ KR & B2 & $\begin{array}{l}\text { TG has the greater power to buy green products } \\
\text { and services, thus enhancing financial benefits for } \\
\text { companies }\end{array}$ \\
\hline KA dominating TG/ FL & B1 & $\begin{array}{l}\text { Responsible KAs have more influence to enhance } \\
\text { credibility of companies }\end{array}$ \\
\hline KR dominating GVP/ TG/ FL & & $\begin{array}{l}\text { Reputation is classified as an intangible KR } \\
\text { KR has more influence in helping companies to } \\
\text { survive by improving efficiency }\end{array}$ \\
\hline \multirow[t]{2}{*}{ KR dominating KA } & $\begin{array}{l}\mathrm{B} 1 \\
\mathrm{~B} 2\end{array}$ & $\begin{array}{l}\text { Reputation is classified as an intangible KR } \\
\mathrm{KR} \text { has more influence in improving financial } \\
\text { returns }\end{array}$ \\
\hline & B3 & $\mathrm{KA}$ is not having any direct impact \\
\hline \multirow[t]{3}{*}{ FL dominating GVP/ KA } & B2 & $\begin{array}{l}\text { A well designed FL will increase revenue } \\
\text { generation }\end{array}$ \\
\hline & B3 & $\begin{array}{l}\text { FL has more influence in securing viability of } \\
\text { companies }\end{array}$ \\
\hline & & $\mathrm{KA}$ is not having any direct impact \\
\hline FL dominating TG & B3 & TG is not having any direct impact \\
\hline FL dominating KR & B2 & $\begin{array}{l}\text { A well designed FL has more influence in securing } \\
\text { financial benefits than KR }\end{array}$ \\
\hline
\end{tabular}


Table 6. Dominance interaction matrix

\begin{tabular}{cccccc}
\hline & GVP & TG & KA & KR & FL \\
\hline GVP & --- & B1, B3 & B1, B2, B3 & B2 & B1 \\
TG & B2 & --- & B2 & B2 & --- \\
KA & --- & B1 & --- & --- & B1 \\
KR & B1, B3 & B1, B3 & B1, B2, B3 & --- & B1, B3 \\
FL & B2, B3 & B3 & B2, B3 & B2 & --- \\
\hline
\end{tabular}

Table 7. Dominance matrix - Ranking of GBM elements with reference to benefits

\begin{tabular}{|c|c|c|c|c|c|c|c|c|}
\hline & GVP & TG & $\mathbf{K A}$ & KR & FL & $\begin{array}{c}\text { No. } \\
\text { Dominating } \\
\text { (D) }\end{array}$ & $\begin{array}{l}\text { Net } \\
\text { Dominance } \\
\text { (D - B) }\end{array}$ & $\begin{array}{l}\text { Rank } \\
\text { Dominating }\end{array}$ \\
\hline GVP & - & 2 & 3 & 1 & 1 & 7 & 2 & 2 \\
\hline TG & 1 & - & 1 & 1 & & 3 & -3 & 3 \\
\hline KA & - & 1 & - & - & 1 & 2 & -7 & 4 \\
\hline KR & 2 & 2 & 3 & - & 2 & 9 & 6 & 1 \\
\hline FL & 2 & 1 & 2 & 1 & - & 6 & 2 & 2 \\
\hline No. being & & & & & & & & \\
\hline Dominated & & & & & & 27 (Total & & \\
\hline (B) & 5 & 6 & 9 & 3 & 4 & Interactions) & & \\
\hline
\end{tabular}




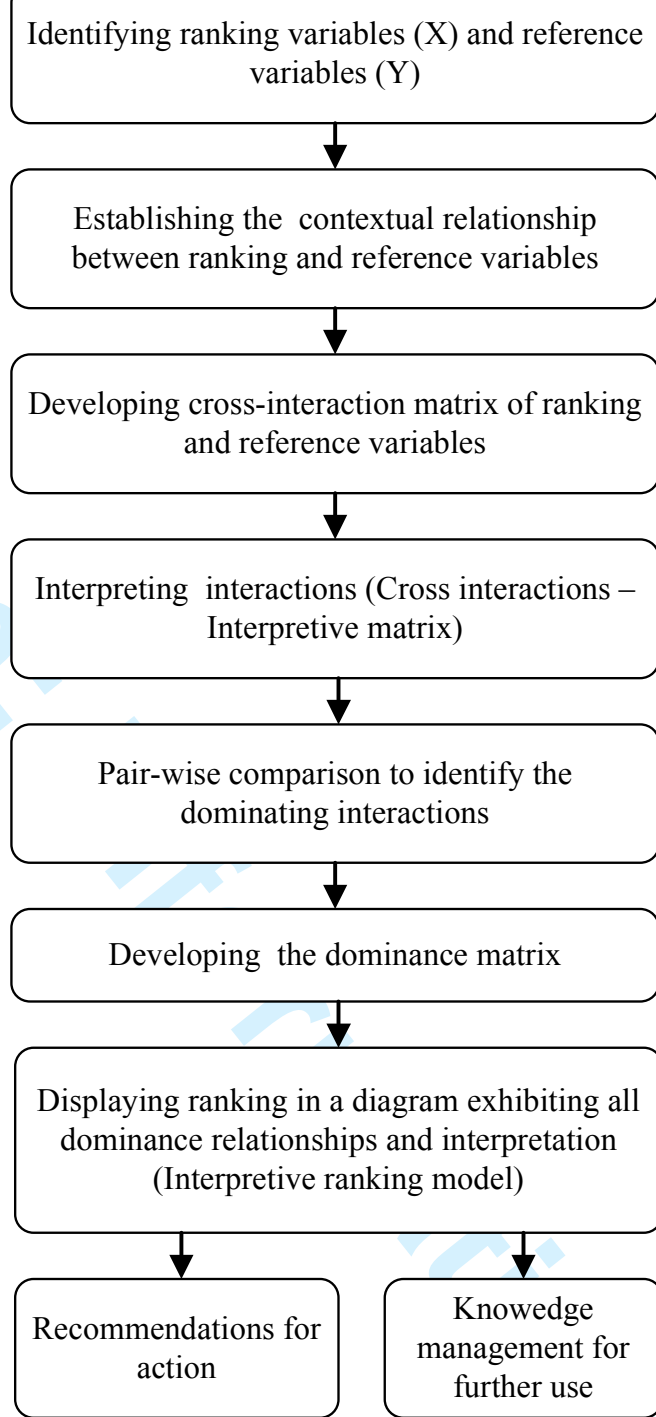

Figure 1. Steps of IRP adapted from (Sushil, 2009) 
Figure 2. Benefits of GBMs

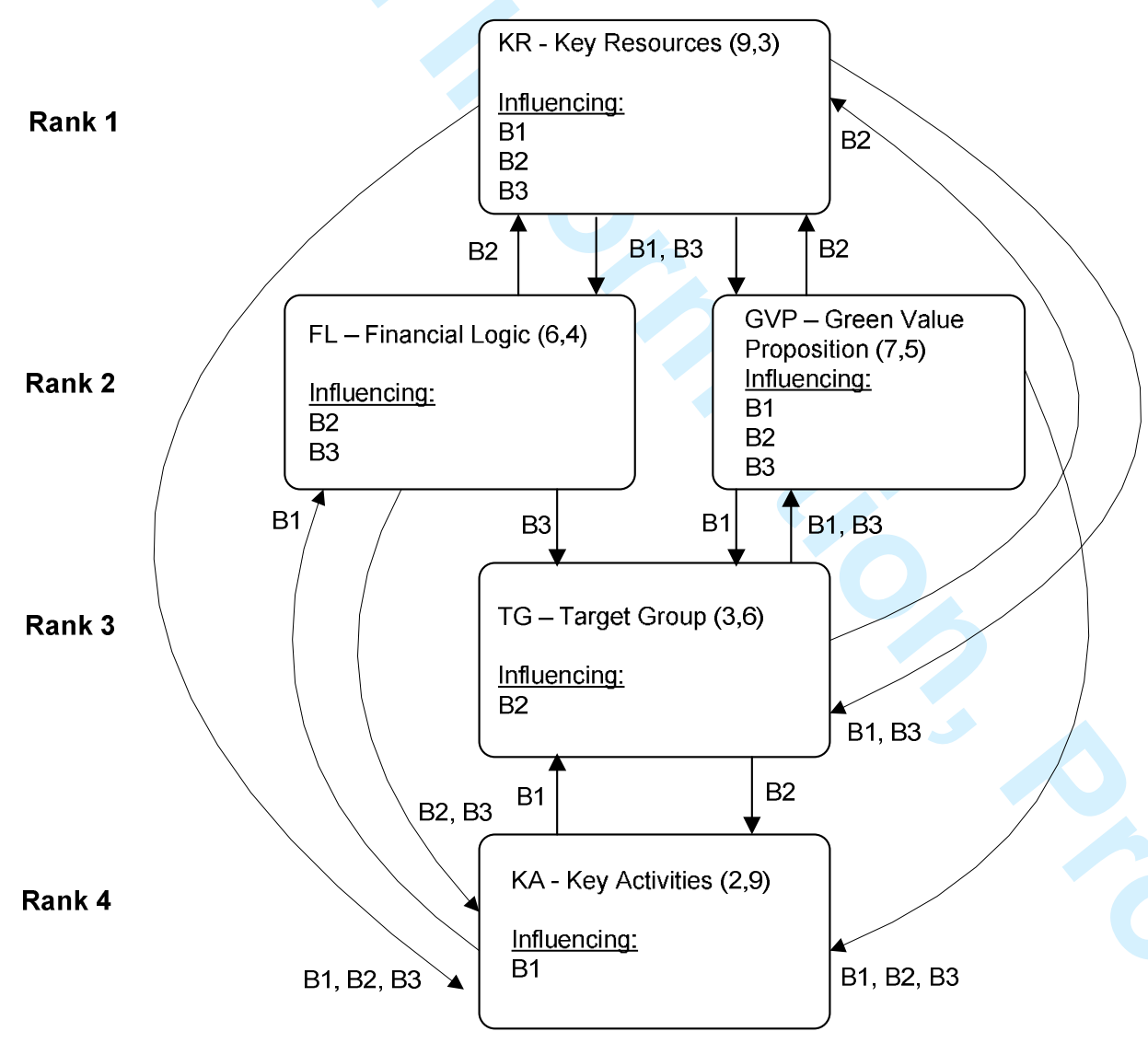

Figure 3. Interpretive ranking model for GBM elements with reference to benefits 